\title{
Frontal bone fracture- A case report
}

\author{
Vidya Holla. ${ }^{1, *}$, Ragavendra Kini ${ }^{2}$, Prasanna. Rao ${ }^{3}$, Devika. N. Shetty ${ }^{4}$, Shree Laxmi Nair ${ }^{5}$ \\ ${ }^{\mathbf{1}}$ Assistant Professor, ${ }^{2} \mathrm{HOD},{ }^{3}$ Professor, ${ }^{4}$ Reader, ${ }^{5}$ Post Graduate, Dept. Oral Medicine and Radiology, A J Institute of Dental \\ Sciences, Kuntikana, Mangalore, Karnataka, India
}

*Corresponding Author:

Email: avholla82@yahoo.co.in

\begin{abstract}
Frontal bone fractures are rare as it is well protected due to prominence of the nasal pyramid and may present with facial deformity and compromised asthetics. It occurs with high impact maxillo facial trauma, maybe associated with ocular discomfort. A three dimensional computed tomography scan may be useful in diagnosing the case and treatment planning. While treating the frontal sinus fracture, patency of the fronto nasal duct is important to avoid formation of mucocele as a late complication.
\end{abstract}

Keywords: Frontal bone fractures, Supra orbital fractures, Frontal sinus fractures, Three dimensional imaging.

\section{Introduction}

Fractures involving frontal bone are rare and are associated with high impact craniofacial trauma. The frontal bone consists of three parts, the squamous part which is the largest and forms majority of the forehead supraorbital margins and the superciliary arch. The orbital portion forms the roof of the orbit and floor of the anterior cranial fossa and articulates with the trochlea of the orbit. The nasal portion articulates with the nasal bone and frontal process of the maxilla to form the root of the nose. ${ }^{1}$ The frontal bone is more protected from traumatic events due to the prominence of the nasal pyramid which protects the naso-orbital region as well as the frontal bone has higher resistance to mechanical impacts. The anterior table of the frontal sinus is normally convex. In cases of high impact trauma, compressive forces on the frontal bone deform the convexity into a concavity. Comminuted fractures can result in trapped mucosa within fracture lines. This can result in sinusitis, or late mucocele formation. Any redundant or injured mucosa at the periphery of the fracture or on isolated bone fragments should thus be removed. $^{2}$

This is a rare case report of an isolated supraorbital rim fracture involving the frontal sinus, wherein a 55 year old male patient came to department with a chief complaint of pain in the left side of the face since three days. Patients gave history of fall three days back following which left side of the face hit the floor. There was history of bleeding from the nose immediately after the fall and vomiting. No history of loss of consciousness or seizures. On extraoral examination, a depression was seen over the left supraorbital ridge region and mouth opening appeared normal. There was no tenderness or deviation on opening and closing the mouth. No tenderness on palpation of zygomatic arch and infraorbital region. There was tenderness on palpation of left supraorbital region with step deformity and depression seen. There was tenderness seen on the left side frontal bone region. There was subconjunctival hemorrhage seen in the right side.

On intraoral examination, it was seen that the maxillary arch and mandibular arch was partially edentulous. No presence of bony irregularities or tenderness. There were no occlusal derangements. Based on patient history and clinical examination, a provisional diagnosis of supraorbital rim fracture was given. The conventional posterior anterior radiological view did not appreciate any abnormalities. The computed tomography examination revealed, fracture of the left frontal sinus. A three dimentional view revealed a depressed frontal bone fracture. There was left side supraorbital rim fracture in the left side. A final diagnosis of left supraorbital rim and frontal sinus fracture was given and patient was referred for surgical evaluation.

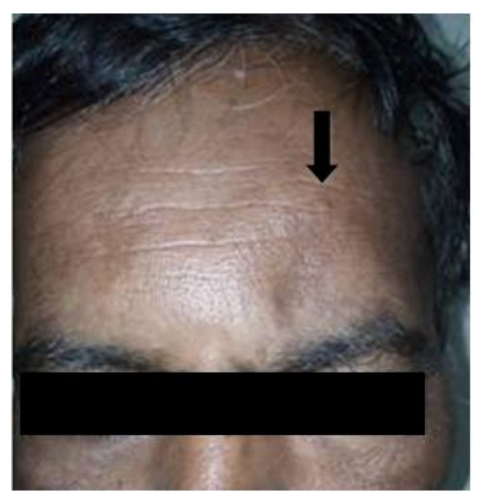

Fig. 1: Patient forehead on the left side showing depression 


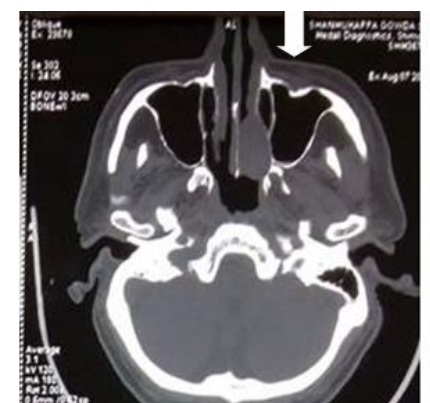

Fig. 2a:

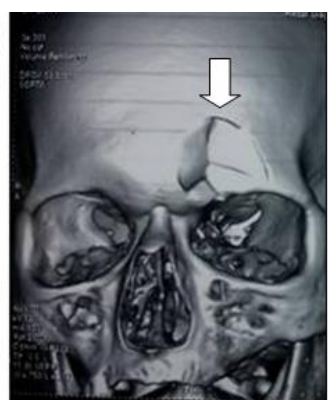

Fig. 2b:

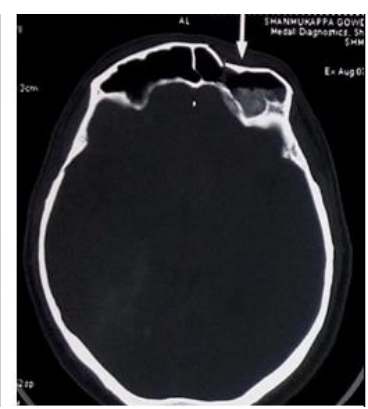

Fig. 2c:

Fig. 2a: CT axial section showing supraorbital fracture; 2b: Communited fracture on the left side forehead; 2c: CT axial section showing frontal bone fracture with homogenecity suggesting post traumatic haemorrage

\section{Discussion}

Frontal bone fractures are rare and occur in only 5$12 \%$ of maxillofacial traumas. An estimated 1\% to $9 \%$ of facial fractures can involve the supraorbital rims and the anterior table of the frontal sinus. The degree of association has been reported to be $95 \%$ with fractures of the anterior table or wall of the frontal sinuses, $60 \%$ with the orbital rims, $60 \%$ with complex injuries of the naso-orbital-ethmoid region, $33 \%$ with other orbital wall fractures and 27\% with Le Fort level fractures. ${ }^{3}$ Apart from high-energy impacts, motor vehicle collisions many other causes have been identified like tire explosions, ruptured garage door springs, chain saws, high-voltage electric shocks, swinging objects and falls from high places. ${ }^{3}$

\section{Classification}

Frontal bone fractures are classified as ${ }^{4}$ -

Table 1:

\begin{tabular}{|l|l|l|}
\hline $\begin{array}{l}\text { Type 1 } \\
\text { fractures }\end{array}$ & $\begin{array}{l}\text { Non- } \\
\text { vertical } \\
\text { fractures }\end{array}$ & $\begin{array}{l}\text { Fractures were defined as } \\
\text { comminuted fractures of } \\
\text { the frontal sinus without a } \\
\text { vertical trajectory. }\end{array}$ \\
\hline $\begin{array}{l}\text { Type 2 } \\
\text { fractures }\end{array}$ & $\begin{array}{l}\text { Vertical } \\
\text { fractures }\end{array}$ & $\begin{array}{l}\text { Fractures are vertical } \\
\text { fractures involving the } \\
\text { orbit but not the frontal } \\
\text { sinus. }\end{array}$ \\
$\begin{array}{l}\text { Type 3 } \\
\text { fractures }\end{array}$ & & $\begin{array}{l}\text { Vertical fractures involving } \\
\text { the frontal bone and sinus } \\
\text { but not the orbit. }\end{array}$ \\
$\begin{array}{l}\text { Type 4 } \\
\text { fractures }\end{array}$ & $\begin{array}{l}\text { Fractures involve both the } \\
\text { frontal sinus and the } \\
\text { ipsilateral orbit. }\end{array}$ \\
$\begin{array}{l}\text { Type 5 } \\
\text { fractures }\end{array}$ & $\begin{array}{l}\text { Fractures cross the midline } \\
\text { of the face, involving the } \\
\text { frontal sinus and the } \\
\text { contralateral or bilateral } \\
\text { orbits. }\end{array}$ \\
\hline
\end{tabular}

The depth of skull base extension was also classified for all fractures as follows:-
Table 2:

\begin{tabular}{|l|l|}
\hline Depth A & $\begin{array}{l}\text { Involvement of the frontal bone } \\
\text { without extension into the skull } \\
\text { base. }\end{array}$ \\
\hline Depth B & $\begin{array}{l}\text { Characterized by extension into } \\
\text { the anterior cranial fossa (orbital } \\
\text { roof, fovea ethmoidalis, } \\
\text { cribriform plate) }\end{array}$ \\
\hline Depth C & $\begin{array}{l}\text { Fractures extend into the middle } \\
\text { cranial fossa (sella, sphenoid } \\
\text { body, carotid canal, optic chiasm } \\
\text { sulcus). }\end{array}$ \\
\hline Depth D & $\begin{array}{l}\text { Fractures involve the posterior } \\
\text { cranial fossa (clivus, } \\
\text { petromastoid temporal bone, } \\
\text { petrosal segment of the carotid } \\
\text { canal). }\end{array}$ \\
\hline
\end{tabular}

After the trauma, the patient may manifest with a flattened or depressed supra orbital ridge. These injuries may present with intensely turgid periorbital ecchymoses, edema, soft tissue lacerations and paresthesia over the area of distribution of the supraorbital and supratrochlear nerves. If the fractures aredisplaced orbitally then, enophthalmos, exophthalmos and proptosis may be noted, along with diplopia. Ocular discomfort, epiphora, limitation of eye movement, increased scleral show and increased width of the palpebral fissure have also been reported. ${ }^{3}$

An extra oral conventional radiographs or computed tomography [CT] scan can be used to evaluate bony defects of the supraorbital rim to decide about their treatment. A three-dimensional CT may provide an excellent detail than a simple CT scanning for the assessment of orbital fractures. Any damage to the posterior table of the frontal sinus can be ruled out by CT. If there is a displaced fracture of the posterior table, then a dural tear is quite possible. ${ }^{3}$

In this case, there was supra orbital rim fracture along with fracture of the anterior table involving frontal sinus caused due a high impact fall. There was a comminuted fracture of the frontal sinus without a vertical trajectory of Type I variety. There was only flattened or depressed supra orbital ridge with absence 
of any periorbital ecchymoses, soft tissue involvement, or ocular disturbances seen. On investigation, an extra oral posterior -anterior view did not reveal any significant changes due to superimposition. However, a 3-dimensional CT revealed a communited left supra orbital ridge fracture. On axial section, there was fracture involving the anterior table of the frontal sinus. The CT also revealed that there were hyperdense areas seen in the postero lateral aspect of the left frontal sinus corresponding to the haematoma formation following trauma.

The aim of frontal sinus fracture management is to create a safe sinus, restore facial contour, aesthetics and avoid short and long term complications. A non displaced supraorbital rim fracture, generally requires no surgical intervention other than soft tissue injuries management. When the fractured segments are displaced, surgical exploration, reduction and stabilization are indicated. Supra orbital rim fractures frequently involve the frontal sinus. The reduction is often stable once the fragments are levered into position, as there are no associated muscular displacing forces. If the anterior table of the frontal sinus and the supraorbital rim are displaced, then operative treatment is required. ${ }^{3}$ The primary decision criteria for surgical intervention are the degree of fracture displacement and the presence of a CSF leak. Patients with posterior table displacement less than one table width and no CSF leak present may be observed. Long-term follow-up with repeat CT scans at 2 months and 1 year is appropriate to rule out mucocele formation. ${ }^{5}$

Proper primary reconstruction and subsequent healing is important to prevent any kind of facial deformity. If the soft tissues are not adequately supported it may lead to shrinkage, thickening and malposition of landmarks. The aesthetic forehead contour is also an important consideration in repair. Past surgical modalities that removed the anterior bony frontal surface left life-long disfiguring defects and have been largely replaced by techniques that leave a smooth contour without visible scars.

The peculiarity of frontal bone fractures is that, inadequate treatment could not only encompass functional or aesthetical problems but also more dangerous complications such as the risk of infections like meningitis, mucocele, encephalitis and cerebral abscess. ${ }^{6}$ If the involvement of the fracture is limited to the anterior table of the frontal sinus, then an assessment of the fronto-nasal duct is important to ensure continued drainage of the frontal sinus after fracture reduction. It helps to prevent the formation of a mucocele of the frontal sinus, which could result in the formation of a mucopyocoele, a delayed but serious infectious complication. ${ }^{3}$ These patients, therefore, require long-term follow-up. In patients who are at high risk of not returning for follow-up evaluation, cranialization of the frontal sinus with complete removal of all mucosal elements may be necessary to eliminate the risk of later mucocele formation.

\section{Conclusion}

This is a case report of an uncommon frontal bone fracture involving the sinus. Here, the main concern would be to maintain the aesthetics and reduce the complication of mucopyocele formation by long term follow up. However, the importance of three dimensional imaging modality can be appreciated which has led to accurate diagnosis and aids in management.

\section{References}

1. Neil S Norton. Netter's head and neck anatomy for dentistry. e book pg 28.

2. Surya Rao RVM, Durairaj AR, Sundaramurthy N, Jesudasan JS. Frontal bone fractures - a report of three different methods of fixation: a case series. Int Surg J 2017;4:3162-5.

3. Taylor P. McGuire, Petrus P. Gomes, Cameron M.L. Clokie, George K.B. Sándor, Fractures of the Supraorbital Rim: Principles and Management J Can Dent Assoc 2006; 72(6):537-40.

4. Garg RK, et al., A novel classification of frontal bone fractures: The prognostic significance of vertical fracture trajectory and skull base extension, Journal of Plastic, Reconstructive \& Aesthetic Surgery (2015).

5. E. Bradley strong. Frontal sinus fractures: current concepts. Craniomaxillofacial trauma \& Reconstruction. Volume 2, number 3/4.2009.

6. Oannides $\mathrm{CH}$, Freihofer HP, Friens J. Fractures of the frontal sinus: a rationale of treatment. Br J Plastic Surg. 1993;46:208-14. 